\title{
Evaluation of a quality improvement intervention for obstetric and neonatal care in selected public health facilities across six states of India
}

\author{
Enisha Sarin ${ }^{1 *}$, Subir K. Kole ${ }^{2}$, Rachana Patel ${ }^{3}$, Ankur Sooden ${ }^{4}$, Sanchit Kharwal ${ }^{5}$, Rashmi Singh 6 ,
} Mirwais Rahimzai ${ }^{7}$ and Nigel Livesley ${ }^{8}$

\begin{abstract}
Background: While increase in the number of women delivering in health facilities has been rapid, the quality of obstetric and neonatal care continues to be poor in India, contributing to high maternal and neonatal mortality.

Methods: The USAID ASSIST Project supported health workers in 125 public health facilities (delivering approximately 180,000 babies per year) across six states to use quality improvement (QI) approaches to provide better care to women and babies before, during and immediately after delivery. As part of this intervention, each month, health workers recorded data related to nine elements of routine care alongside data on perinatal mortality. We aggregated facility level data and conducted segmented regression to analyse the effect of the intervention over time.

Results: Care improved to $90-99 \%$ significantly $(p<0.001)$ for eight of the nine process elements. A significant $(p<0.001)$ positive change of 30-70\% points was observed during post intervention for all the indicators and 3-17\% points month-to-month progress shown from the segmented results. Perinatal mortality declined from 26.7 to 22.9 deaths/1000 live births $(p<0.01)$ over time, however, it is not clear that the intervention had any significant effect on it.
\end{abstract}

Conclusion: These results demonstrate the effectiveness of Ql approaches in improving provision of routine care, yet these approaches are underused in the Indian health system. We discuss the implications of this for policy makers.

Keywords: Quality improvement, Obstetric care, Neonatal care, Health care delivery, Health system strengthening, India

\section{Background}

Since the launch of the conditional cash transfer programme, Janani Suraksha Yojana (JSY), the percentage of women delivering in institutions in India increased from $56.7 \%$ in 2006 to $78.5 \%$ in 2011 [1]. However, maternal mortality and neonatal mortality did not decrease commensurately. An analysis of annual health survey data from nine states found no association between institutional birth proportion and maternal mortality. The

\footnotetext{
* Correspondence: esarin@jhsph.edu

${ }^{1}$ Consultant, University Research Company, India Pvt. Ltd B7, 1st floor,

Suncity, Gurgaon 122002, Haryana, India

Full list of author information is available at the end of the article
}

authors suggested that this could be due to poor quality of services [2]. Other studies have found evidence to support the contention that poor quality of care explains why mortality remains high, reporting lack of routine care, absence of organized preparation to conduct birth, staff abuse and neglect of women during delivery [3], lack of skilled birth attendants, referrals that did not result in treatment [4], and low competence among staff to manage obstetric complications $[4,5]$.

There are also concerns with quality of care for neonates and infants. Available evidence from facilities in India and other South Asian settings point to low rates 
of asphyxia management [6] and low coverage of immediate breastfeeding and thermal care [7].

These data support the premise that poor quality of care is a major contributor to maternal and newborn mortality in India. Therefore, there is an urgent need for approaches which can support providers to deliver better care. A recent publication lists various strategies to improve service delivery [8]. These include development of standards and guidelines, changing organizational structures, education and training, process improvement, providing incentives, changing organizational culture, and leadership or management interventions [8].

The Indian public health system uses most but not all of these approaches to improve maternal and neonatal health. Standards and guidelines exist [9]; new organization structures such as the national $\mathrm{RMNCH}+\mathrm{A}$ unit (NRU) and State RMNCH + A units (SRU) have been formed to focus on maternal and neonatal health [10]; there are extensive in-service training programs; incentives, campaigns and institutional frameworks include quality issues [11]; and many inspection/monitoring systems exist. Despite the use of this diverse set of interventions, process or quality improvement methods are underused.

Quality improvement (QI) is a management approach that equips health workers with the skills that allow them to change how they work to ensure that they can apply evidence-based practice [12]. QI is based on the principles of focusing on the client's outcomes, thinking in terms of systems and processes, teamwork, using data to guide decision making, and iterative testing to change service delivery [13].

Between January 2014 and November 2015, the USAID Applying Science to Strengthen and Improve Systems (ASSIST) Project worked with 125 public health facilities across six states in India which deliver approximately 180,000 babies per year. The project supported health care staff to use QI approaches to redesign processes and ensure that appropriate care was delivered. In this paper, we report on the efforts to improve elements of routine care using QI approaches.

\section{Methods}

\section{Intervention sites}

In collaboration with the Ministry of Health and Family Welfare, we supported 27 high priority districts in six states - Delhi, Haryana, Himachal Pradesh, Jharkhand, Punjab, and Uttarakhand. Hence, the selection of intervention sites are purposive in nature. $\mathrm{MoH}$ had identified these districts based on selected key performance indicators in RMNCHA domain. These comprised the bottom quintile of all districts in each state in terms of performance and also took into account equity concerns. Within these districts, we planned to have an impact on maximum number of deliveries that was possible for one coach in every district to handle. In each district, we worked at the district hospital, sub district hospital/s, and all primary and community health centres in a block selected on the following criteria: 1) willingness of block leaders to implement a QI project, 2) accessibility, and 3) mid-level performance ${ }^{1}$ on health indicators. This site selection allowed us to work for $50-80 \%$ of child-births occurring in government health facilities in every district. In these facilities, care is provided by nurses, doctors and specialists (OBGYN and Pediatrics) who composed a QI team. Whenever required and available, additional staff such as pharmacist, helpers, ASHAs (community health workers), facility head, and auxiliary nurses were involved.

\section{Description of the QI intervention}

After identification of facilities, project staff provided initial training to health workers and managers on the seven steps of quality improvement, laid down in a QI Implementation guide [14]. This included an introduction to how to: 1) identify an improvement goal, 2) form and work in a team, 3) analyze current systems of care to identify the reasons for poor care, 4) develop simple measurement systems, 5) develop options for possible solutions, 6) test these interventions on a small scale, 7) implement the interventions that were found to be successful. Interventions covered systemic and process changes including facility improvement, supplies of medicines, improved record keeping and so on depending on the nature of the problem identified.

After the initial training, project staff visited facilities roughly every month to provide hands-on support to health workers in applying these skills to identify and solve problems of patient care. The project employed one coach per district to provide this ongoing support. Initially, facility staff were encouraged to choose improvement goals involving routine care (preventative, diagnostic, or management interventions) that all pregnant and post-partum women and all neonates should receive. In this paper, we look at the effect of the QI support on nine elements of routine care and perinatal mortality.

\section{Data collection}

Data were self-collected by the teams of health workers and came from existing hospital records which included patient case files, ANC cards and delivery registers. These data are routinely collected as part of the ANC, delivery and post partum procedures, and we did not collect additional data. Each month, project staff verified and recorded data in a predesigned Excel database. Data were then aggregated at district, state, and finally at aggregate level, with data verification at each step. 
Additional files are attached to Additional file 1 indicate proportion of services (indicators) conducted, and Additional file 2 to show aggregate number of patient records reviewed for ANC, delivery and newborn care across all months. Because facilities only reported data related to the goals that they were working on, the number of facilities reporting data for each indicator varies. Data reporting started as soon as district coaches were hired and QI teams formed, from July 2013 onwards. Most of the indicators were taken up for improvement following the QI model, from January to February 2014. Data collection continued till August 2015 when the project officially closed.

\section{Ethical clearance}

The data pertain to an intervention project and are taken from hospital records that are routinely collected and hence no ethical clearance was required. This was a basic program evaluation that was a routine part of implementation with no additional data collected than would be normally expected in such a program. Anonymity and patients'/clinicians' rights were respected and we had permission from facilities plus $\mathrm{MOH}$ to implement the intervention. Furthermore, as per the national guidelines for biomedical research, "research on publicly available information, documents, records, works, performances, reviews, quality assurance studies, archival materials or thirdparty interviews, service programs for benefit of public having a bearing on public health programs, and consumer acceptance studies" are waived from voluntary informed consent process [15]. The use of data for a quality improvement intervention falls in the above mentioned category.

\section{Measures}

For tracking the progress of our intervention, we selected a set of nine process indicators spread across four domains of antenatal (ANC), intrapartum, essential newborn care (ENC), and postpartum care. These indicators were chosen based on prior experience of the implementers about which elements of care are good to teaching health workers how to use QI approaches. Facility staff chose new indicators to work on as their skills grew based on what they perceived to be priorities in their facilities, which are not presented in this analysis as the start time differs. The current analysis focuses on the nine process indicators that the QI teams worked on at the start of the USAID ASSIST support. Additionally, we included perinatal mortality indicator to see the effect of the intervention. The specific indicators were:
ANC:

1. Proportion of antenatal care visits (ANCs) during which the hemoglobin of pregnant woman was documented;

2. Proportion of ANCs during which history was taken to rule out high-risk pregnancy;

3. Proportion of ANCs during which counseling about nutrition, family planning, breastfeeding was documented.

Intrapartum:

4. Proportion of vaginal deliveries for which a uterotonic was administered within one minute of birth of baby.

Essential newborn care:

5. Proportion of newborns made dry and provided warmth immediately after birth;

6. Proportion of newborns provided sterile cutting and clamping of cord;

7. Proportion of newborns breastfed within one hour of birth;

8. Proportion of newborns given injection of vitamin $\mathrm{K}$ within $24 \mathrm{~h}$ of birth.

Postpartum Care:

9. Average number of times blood pressure and pulse rate were recorded within the first six hours after delivery.

\section{Outcome Measure:}

10.Perinatal mortality rate calculated by totaling neonatal deaths and still births over the total number of live births in a facility.

\section{Data analysis \\ Trend analysis}

Most facilities started their QI projects in JanuaryFebruary 2014, with baseline data collected for the preceding months. Therefore, we have month 8 (February 2014) as the cutoff point preceding which is baseline data and following which is intervention data. Table 1 shows the number of facilities reporting on selected indicators, which varies as new facilities get added up or older facilities may stop reporting once they have achieved their goal.

Firstly, to explore time trend from July 2013 to August 2015, we aggregated data from all states at the national 
Table 1 Number of facilities reporting data

\begin{tabular}{|c|c|c|c|c|c|c|c|c|c|}
\hline \multicolumn{10}{|c|}{ Number of facilities covered } \\
\hline Months & $\mathrm{Hb}$ check & History taken & $\begin{array}{l}\text { ANC } \\
\text { counseling }\end{array}$ & $\begin{array}{l}\text { Keep new born } \\
\text { dry and warm }\end{array}$ & $\begin{array}{l}\text { Sterile Cord } \\
\text { care }\end{array}$ & Vitamin K & $\begin{array}{l}\text { Early Breast } \\
\text { feeding }\end{array}$ & $\begin{array}{l}\text { Oxytocin } \\
\text { given }\end{array}$ & $\begin{array}{l}\text { Postnatal vitals } \\
\text { check }\end{array}$ \\
\hline Jul-13 & 50 & 41 & 39 & 58 & 59 & 83 & 72 & 101 & 74 \\
\hline Aug-13 & 52 & 43 & 40 & 58 & 59 & 83 & 72 & 101 & 74 \\
\hline Sep-13 & 52 & 43 & 40 & 58 & 59 & 83 & 72 & 101 & 74 \\
\hline Oct-13 & 53 & 44 & 41 & 58 & 59 & 83 & 72 & 101 & 74 \\
\hline Nov-13 & 54 & 44 & 41 & 58 & 59 & 83 & 72 & 101 & 74 \\
\hline Dec-13 & 56 & 46 & 44 & 58 & 59 & 83 & 72 & 101 & 74 \\
\hline Jan-14 & 69 & 54 & 53 & 58 & 59 & 83 & 72 & 101 & 74 \\
\hline Feb-14 & 73 & 56 & 53 & 62 & 63 & 89 & 82 & 102 & 84 \\
\hline Mar-14 & 73 & 55 & 53 & 74 & 75 & 99 & 86 & 111 & 88 \\
\hline Apr-14 & 71 & 48 & 46 & 70 & 70 & 100 & 86 & 115 & 87 \\
\hline May-14 & 58 & 36 & 34 & 58 & 59 & 102 & 74 & 116 & 78 \\
\hline Jun-14 & 57 & 35 & 33 & 57 & 58 & 109 & 74 & 117 & 87 \\
\hline Jul-14 & 44 & 22 & 20 & 53 & 54 & 109 & 77 & 116 & 88 \\
\hline Aug-14 & 46 & 24 & 22 & 54 & 55 & 109 & 81 & 118 & 91 \\
\hline Sep-14 & 46 & 24 & 22 & 53 & 54 & 107 & 86 & 118 & 90 \\
\hline Oct-14 & 49 & 26 & 24 & 52 & 53 & 107 & 89 & 117 & 90 \\
\hline Nov-14 & 51 & 28 & 26 & 51 & 52 & 107 & 90 & 117 & 90 \\
\hline Dec-14 & 51 & 28 & 26 & 51 & 52 & 108 & 90 & 118 & 91 \\
\hline Jan-15 & 49 & 26 & 24 & 51 & 52 & 102 & 84 & 111 & 91 \\
\hline Feb-15 & 49 & 26 & 24 & 51 & 52 & 102 & 84 & 111 & 91 \\
\hline Mar-15 & 50 & 27 & 25 & 51 & 52 & 108 & 90 & 117 & 91 \\
\hline Apr-15 & 49 & 26 & 24 & 51 & 52 & 108 & 90 & 117 & 91 \\
\hline May-15 & 45 & 26 & 24 & 51 & 52 & 108 & 89 & 117 & 90 \\
\hline Jun-15 & 45 & 26 & 24 & 51 & 52 & 108 & 89 & 117 & 90 \\
\hline Jul-15 & 40 & 26 & 24 & 49 & 50 & 103 & 84 & 109 & 85 \\
\hline Aug-15 & 40 & 26 & 24 & 49 & 50 & 101 & 82 & 107 & 84 \\
\hline
\end{tabular}

level for selected indicators, calculated proportions, and plotted them on graphs.

Secondly, facility-wise data were aggregated at state level for the entire time period (26 time points) and then transferred to Stata version 13.1 for segmented regression analysis. This analysis was conducted to see the effect of the intervention on service delivery at various points of the project life.

\section{Estimating changes in level and trend: segmented regression}

To assess chance and control for other effects, segmented regression analysis was used. Each segment of the series was allowed to exhibit both a level and a trend that followed an intervention. This statistical model estimates level and trend in the pre-intervention segment and changes in level and trend after the intervention.

$$
\begin{aligned}
Y_{t} & =\beta_{0}+\beta_{1} * \text { time }_{t}+\beta_{2} * \text { intervention }_{t} \\
& +\beta_{3} * \text { timeafter intervention } \\
& +\varepsilon_{t}
\end{aligned}
$$

Here, $\mathrm{Y}_{\mathrm{t}}$ is the proportion of women obtained services for selected health indicator under QI measures in month $\mathrm{t}$; time is a continuous variable at time $\mathrm{t}$ from the start month of the observation period; intervention is an indicator for time $\mathrm{t}$ occurring before (intervention $=0$ ) or after (intervention =1) the cap, which was implemented at month 8 in the series; and time after intervention is a continuous variable counting the number of months after the intervention at time $t$, coded 0 before the cap and (time-9) after the cap.

In this model, $\beta_{0}$ estimates the baseline level of the outcome at time $0 ; \beta_{1}$ estimates the change in the proportion that occurs with each month during the 
intervention; $\beta_{2}$ estimates the level change in the proportion immediately after the intervention, that is, from the end of the preceding segment; and $\beta_{3}$ estimates the change in the trend in the proportion after the cap. The error term $e_{t}$ at time $t$ normally distributed random error that may be correlated to errors at preceding or subsequent time points [16-18].

\section{Results}

We present the results in trend charts which uses data aggregated from all six states at the national level. Furthermore, we present the segmented regression analysis which uses data from all facilities at the state level. Overall, bivariate analysis shows that the process indicators improved significantly post intervention compared to pre intervention (Table 2).

\section{Antenatal care practices}

Performance of desired antenatal care practices increased considerably over the intervention period (Fig. 1). Segmented regression results (Table 3) indicate that just before the beginning of the observation period, on average $40 \%$ (adjusted for time and intervention) of women went for $\mathrm{Hb}$ test. With time, there was significant month-to- month change of 0.04 in the proportion of Hb test $(P<0.014))$ and even right after the cap, the estimated proportion increased abruptly by 0.17 . There was no significant change in the month-to-month trend in the mean number of tests after the cap, as the trend of approximately $85 \%$ was maintained across the months of intervention. Proportion of ANC history taking increased by 0.30 over time with the intervention having a significant impact $(P<0.001)$. Similarly, ANC counseling significantly increased over time as well as during the time after intervention by $0.025(P<0.001)$.

\section{Intrapartum care}

Similar results to antenatal practices regression model explains the proportion of women given oxytocin within one minute of delivery, proportion of newborns kept dry \& warm, sterile cord care, early breastfeeding and vitamin K provided were significantly $(p<0.001)$ increased by $20-70 \%$ during post intervention period and monthto-month significant $(p<0.001)$ improvement $(3-13 \%)$ was also observed (Table 3 ). As can be seen from the time series chart (Figs. 2, 3 and 4), the indicators began to increase during the preparatory phase of the intervention while after February 2014, except Vitamin K, the provision of all other practices stabilized at around 90\% during the early months of intervention (breastfeeding at around 85\%). Vitamin K provision, however, kept increasing significantly from month to month during the period of intervention $(p<0.01)$. It took $8-9$ months to increase vitamin $\mathrm{K}$ injection from 40 to $70 \%$, after which it was sustained at $98 \%$ until the end of the project.

\section{Postpartum care}

Postpartum care in terms of checking of mother's vitals also improved over the intervention. The average number of times that blood pressure and pulse was checked for a woman within $6 \mathrm{~h}$ after delivery increased from 0.3 to 3.5 times (Fig. 3). Segmented regression analysis shows that while post intervention had a significant impact in its increase $(75 \%, p<0.05)$, there was no significant increase in the month to month trend during the period of intervention.

While perinatal mortality decreased as a function of time $(P<0.01)$, the pre-post intervention showed no significant impact, nor did the trend show any month to month change during the period of intervention (Table 3).

In general results from segmented model confirms month-to-month and pre-post intervention period significant improvement in health care indicators whereas trend after intervention did not have the same effect in variation (barring some indicators) which is probably due to a rapid and huge increase in the early phase of intervention following which many of the indicators stabilized at a constant rate.

Table $\mathbf{2}$ Test of means of measures by intervention group

\begin{tabular}{|c|c|c|c|c|}
\hline Measures & Prior to intervention & During intervention & Aggregate & $p$ (ttest) \\
\hline Hemoglobin checked & 0.53 & 0.87 & 0.77 & 0.0000 \\
\hline ANC history taken & 0.12 & 0.77 & 0.58 & 0.0000 \\
\hline ANC counseling & 0.05 & 0.71 & 0.50 & 0.0000 \\
\hline Oxytocin within 1 min & 0.19 & 0.95 & 0.74 & 0.0000 \\
\hline Kept baby DRY \& warm & 0.36 & 0.98 & 0.83 & 0.0000 \\
\hline Sterile cord care & 0.36 & 0.97 & 0.84 & 0.0000 \\
\hline Early breastfeeding & 0.35 & 0.95 & 0.79 & 0.0000 \\
\hline Vitamin K & 0.76 & 0.90 & 0.87 & 0.0000 \\
\hline Average no. of times PNC & 0.69 & 3.01 & 2.35 & 0.0000 \\
\hline Perinatal Death Rate (per1000 live births) & 26.73 & 22.92 & 24.09 & 0.0084 \\
\hline
\end{tabular}


Progress of ANC Indicators

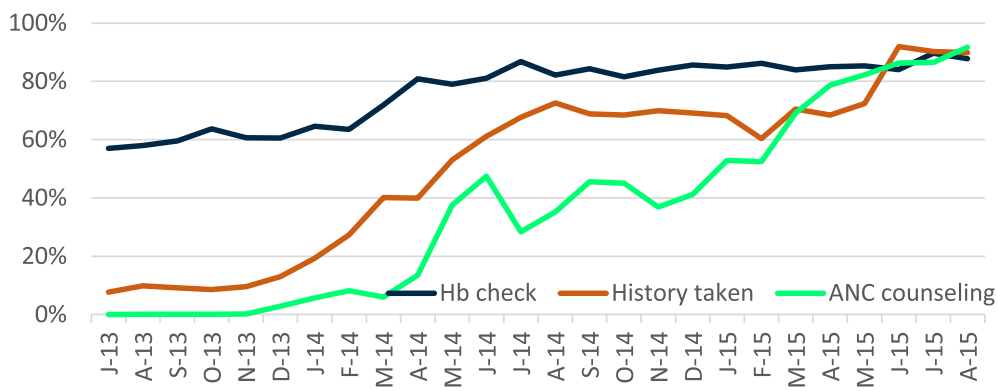

Fig. 1 Trend in ANC indicators over baseline and intervention period (July 2013- August 2015)

\section{Discussion}

There is growing interest in how to improve quality of care for maternal and newborn health in developing countries [19]. Most literature that exists focuses on single interventions such as training, audits, guidelines, or improving facility infrastructure [20-24], and ignores the growing body of evidence that draws from scientific management approaches, particularly those developed in the auto industry, which performs very well on quality measures $[25,26]$.

This paper addresses this gap in the literature by describing how a QI approach led to improved processes of care across a wide range of clinical areas and wide range of clinical contexts (rural, urban, large, small, etc.). Health workers in selected facilities in 27 districts with a combined population of 32 million people were supported to use QI approaches by externally funded QI coaches (1 per district). This approach rapidly led to significant improvements in care. We have not assessed the sustainability of this work after the project ended but various governments are currently using their own funds to replicate the use of coaches providing regular support to help facility staff use QI approaches. In addition, we transferred technical know-how to an Indian NGO that is funded by USAID under the $\mathrm{MOH}$ mandate to scale up and strengthen the efforts that we made.

\section{Antenatal care}

The results clearly demonstrate that teams can use QI approaches to redesign care delivery processes and improve delivery of antenatal care. Most of these improvements involved reorganizing work stations and processes, coupled with improved recording practices aimed at early identification and management or referral for high-risk conditions. For example, in facilities in Himachal Pradesh, ANC triage was improved through redesign of space and task shifting of staff. Previously, crowds of ANC patients would rush into a hall, where depending upon the patient load and number of staff, they may or may not receive the requisite care. After QI implementation, stations and staff were defined for specific activities, which led to less crowding and fewer missed opportunities. Simultaneously, recording of clinical care practices improved [27] Reporting of hemoglobin measurement and obstetric history taking was done diligently, since these indicators were considered

Table 3 Full segmented regression model

\begin{tabular}{lllll}
\hline Health Measures & Intercept & Time & Intervention & Time of Intervention \\
\hline & $\beta_{0}(\mathrm{SE})$ & $\beta_{1}(\mathrm{SE})$ & $\beta_{2}(\mathrm{SE})$ & $\beta_{3}(\mathrm{SE})$ \\
Hemoglobin checked & $0.36(0.071)$ & $0.036^{* *}(0.014)$ & $0.175^{*}(0.071)$ & $-0.031(0.014)$ \\
ANC history taken & $-0.010(0.074)$ & $0.029^{*}(0.014)$ & $0.297^{* * *}(0.074)$ & $-0.002(0.015)$ \\
ANC counseling & $0.047(0.053)$ & $0.024(0.023)$ & $0.439^{* * *}(0.090)$ & $0.025^{* * *}(0.007)$ \\
Oxytocin within 1 min & $-0.070(0.049)$ & $0.056^{* * *}(0.009)$ & $0.495^{* * *}(0.048)$ & $-0.047^{* * *}(0.010)$ \\
Kept baby DRY \& warm & $-0.353(0.055)$ & $0.131^{* * *}(0.009)$ & $0.259^{* * *}(0.040)$ & $-0.129^{* * *}(0.010)$ \\
Sterile cord care & $-0.346(0.055)$ & $0.130^{* * *}(0.009)$ & $0.242^{* *}(0.040)$ & $-0.127^{* * *}(0.010)$ \\
Early breastfeeding & -0.049 & $0.081^{* * *}$ & $0.281^{* * *}$ & $-0.074^{* * *}$ \\
Vitamin K & $0.940(0.065)$ & $-0.035^{* *}(0.012)$ & $0.202^{* * *}(0.053)$ & $0.039^{* *}(0.012)$ \\
Average no. PNC & $0.107(0.413)$ & $0.125(0.079)$ & $0.747^{*}(0.401)$ & $-0.002(0.082)$ \\
Perinatal Death Rate (per1000 live births) & $31.77^{* *}(2.853)$ & $-1.118^{* *}(0.565)$ & $2.818(2.971)$ & $0.832(.588)$ \\
\hline
\end{tabular}

${ }^{*} p<0.05,{ }^{* *} p<0.01,{ }^{* * *} p<0.001$ 


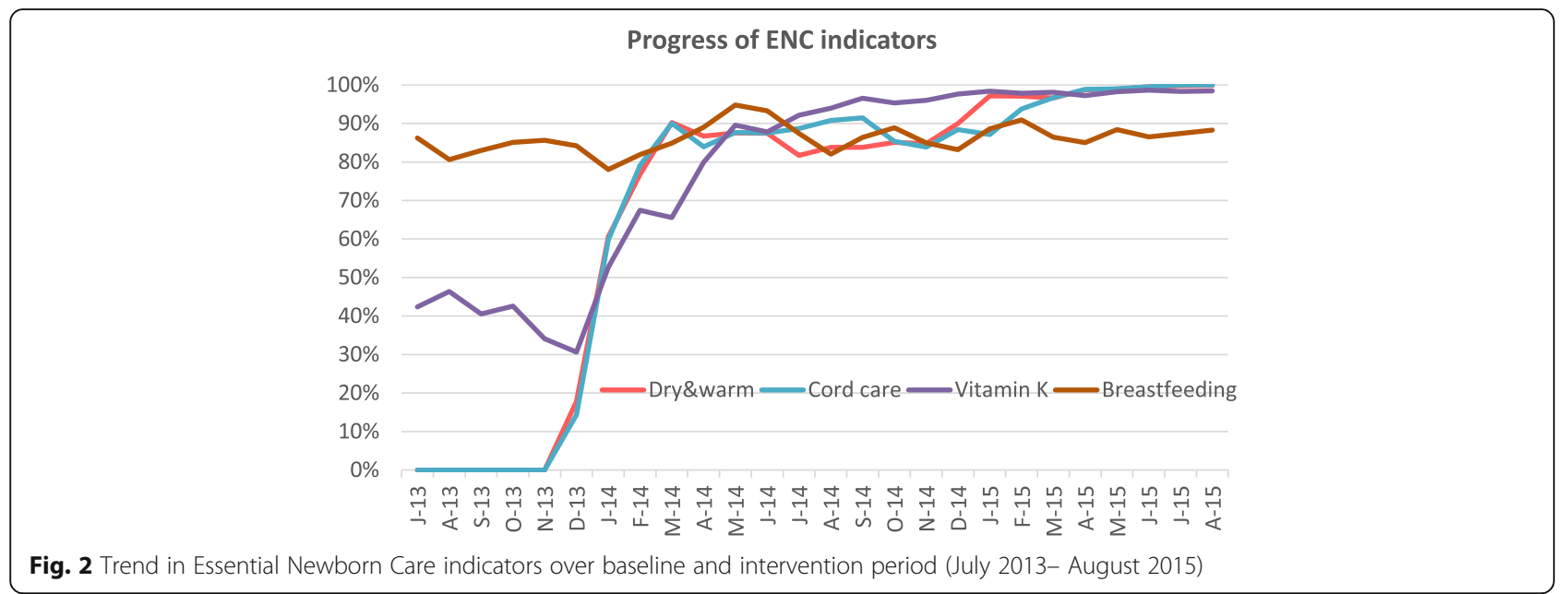

vital for identification of high-risk pregnancy and therefore we see a rapid increase in these processes in the early months of the intervention after which they plateaued. We did not see the same for ANC counseling, exhibited by fluctuating trends, which is considered a routine and mundane job by most staff. It was only after 12 months that counseling showed a gradual improvement; this occurred due to renewed focus on counseling and introduction of guidelines. Our findings are in alignment with another study in Kenya which demonstrated improved adherence to clinical standards of antenatal care, such as measurement of hemoglobin and blood pressure, administration of tetanus toxoid vaccination, and counseling following a QI intervention [28].

\section{Intrapartum care}

We found swift improvement in processes that do not require additional technical skills, are delivered as a single step, and are one-sided (do not involve client compliance issues) such as giving oxytocin within one minute of birth, vitamin $\mathrm{K}$, cord care, and keeping babies dry and warm. For example, improvement could already be seen in oxytocin administration as teams were preparing for the intervention (from 1\% in July 2013 to 57\% in February 2014). Most facilities were able to apply simple changes like prefilling syringes with oxytocin and disseminating information among staff conducting deliveries to improve administration, and therefore we see a quick increase during the early months of intervention up to May 2014 when it reached $90 \%$ and stabilized thereof. Our finding echoes that of another study in Rajasthan where a QI intervention helped increase delivery of oxytocin after birth from 57 to 90\% [29]. Early breastfeeding increased over the intervention period (Table 3). The time series chart at the all state aggregate level shows a high reporting in baseline which actually drops once the intervention starts, probably a result of more accurate reporting, picking up again during intervention after which it does not show any increase month to month during intervention period (Fig. 2). Not reaching $90-100 \%$ can perhaps be explained by the fact that out of all deliveries, there are some which result in extremely sick newborns or sick mothers who are unable to breastfeed. Keeping babies dry and warm

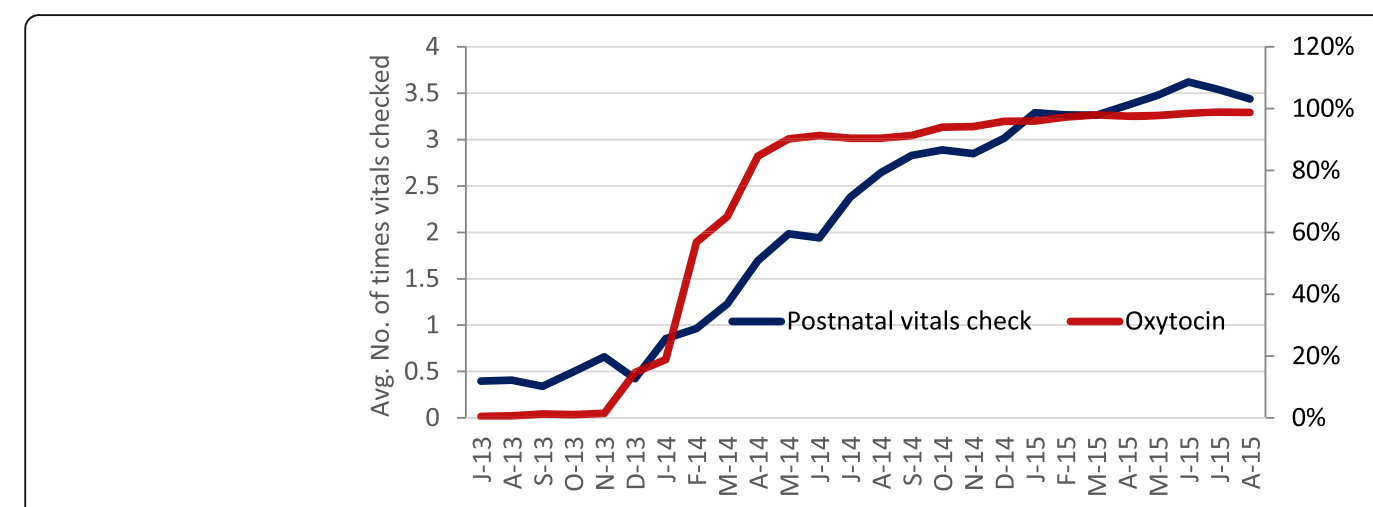

Fig. 3 Trend in Oxytocin administration and maternal vitals monitoring over baseline and intervention period (July 2013- August 2015) 


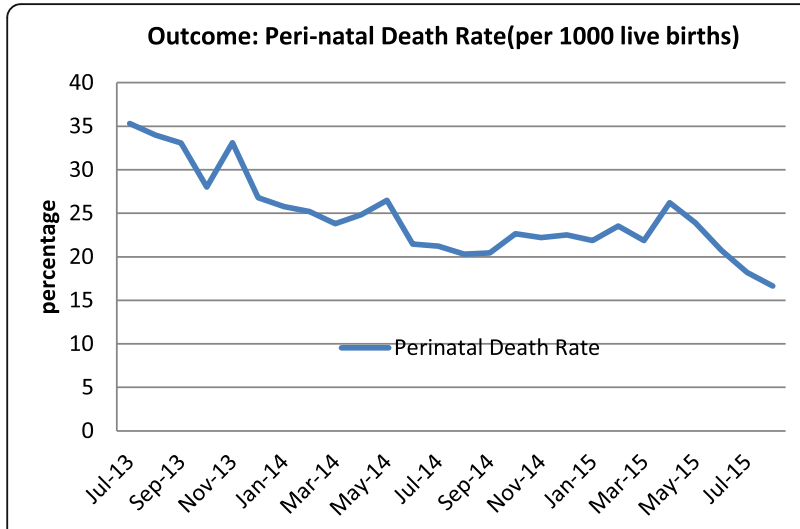

Fig. 4 Trend in perinatal mortality and post- partum hemorrhage over baseline and intervention period (July 2013- August 2015)

increased to cover almost all babies at project end, which was higher than the reported $80 \%$ coverage from the Rajasthan QI study [30]. It could be that our intervention ran for a longer period of time (21 months) during which new steps in improvement had time to become established practices. Facilities were quickly able to raise vitamin $\mathrm{K}$ administration to approximately $90 \%$. Achieving the final $10 \%$ took longer, as teams had to learn how to give vitamin $\mathrm{K}$ to neonates with complications, which required additional care.

\section{Postpartum care}

Although there was increase in the number of vitals check after delivery, not all states demonstrated this increase and hence we did not have statistically significant improvement. Nevertheless, the increase in certain states health staff was achieved by setting a schedule of monitoring vital parameters in the patient's records and documenting it for all cases. In some facilities, vitals monitoring was improved by reorganization of the labor ward and partnering with family members to inform nurses in case of danger signs [30]. This shows that despite shortage of staff, which is reported as the main limitation in carrying out monitoring of heart rate and blood pressure [3], improvement can be made. Specific changes and strategies associated with improvements in all these elements of care were gathered and are currently available online [31].

Although perinatal mortality showed a decline over time, there is no evidence that the intervention had a significant impact on its decline. This may be because there was an insufficient baseline period or the intervention period was not long enough to affect mortality. Alternatively, the decline we observed could simply be due to secular trends.

\section{Limitations}

There are a number of limitations in our study. The number of facilities varied across the intervention, especially those reporting ANC indicators. Circumstantial reasons such as the departure of a district coach or the implementation of a government program that moved staff to other tasks or achievement in the said improvement goal led to less reporting. Nevertheless, we believe that such factors were not extensive enough to influence the overall trend since the number of facilities was still sufficient in terms of in-patient loading to measure improvement during entire intervention period (Table 1). While data were generally obtained from hospital registers, some data were based on observations of 20 patients or a sample of records. This, however, occurred in the initial stage of the intervention. As the said indicator became an established practice, data from hospital registers became the norm. Furthermore, since we did not have sufficient resources to conduct separate interviews with patients, we do not have their perspective of whether and how clinical care was delivered which may affect our interpretation. Future programmes must include user perspective. Another limitation is that while we analyzed data at the state level, we have not presented individual state results due to limitation in text length. Lastly, we could not estimate the effect of external variables, such as the effect of other interventions to improve care. However, no drastic changes to the macro-level factors (policy and program) occurred in the 26-month period under reporting. We therefore believe that this study supports the effectiveness of QI intervention in improving patient care.

\section{Conclusion}

Lack of quality of care is increasingly being recognized as a major contributing factor to maternal and neonatal mortality in India and other countries. Commonly used strategies to improve the quality of service delivery, including standards and guidelines, training, incentives, and monitoring are necessary but they are not the only strategies available to the health sector. The findings from this study suggest that quality improvement methods, including setting a goal, forming a team, and working iteratively to reach that goal can improve the delivery of facility-based routine clinical practices.

\section{Endnotes}

${ }^{1}$ Mid-level performance health indicators are the district level indicators (DLHS-3) and moderately performing facilities in terms of quality are selected assuming to improve under QI intervention plan rather than poorly performing and highly performing, since the poorly performing facilities may not be improved only by QI with the existing infrastructure. 


\section{Additional files}

Additional file 1: File name: State data ASSIST. Title of data: Aggregated statewise data of selected indicators. Description of data: Monthly data on all selected indicators across all states providing numerator and denominator of indicators indicating proportion of services conducted. (XLSX $1763 \mathrm{~kb}$ )

Additional file 2: File Name: Copy of total records reviewed. Title of data: Aggregated monthly patient records. Description of data: The total number of patient records reviewed per month for broad indicators: total number of ANC records reviewed, total number of deliveries reviewed and total number of newborn records reviewed. (XLSX 9 kb)

\section{Abbreviations}

ANC: Antenatal care; ASSIST: Applying science to strengthen and improve systems; ENC: Essential newborn care; JSY: Janani suraksha yojana; QI: Quality improvement; RMNCH + A: Reproductive, maternal, neonatal, child and adolescent health; SRU: State RMNCHA units; USAID: US agency for international development

\section{Acknowledgement}

We are also indebted to Lani Marquez, Edward Broughton, Rashad Massoud and Jim Heiby for their comments on early drafts.

\section{Availability of data and materials}

All data analysed during the intervention are included as supplementary information files in the published article.

\section{Funding}

This work was made possible by the support of the American people through the United States Agency for International Development (USAID) and its Applying Science to Strengthen and Improve Systems (ASSIST) Project, implemented by University Research Co., LLC (URC) under the terms of Cooperative Agreement Number AID-OAA-A-12-00101. USAID has no role in the design of the intervention, data collection, analysis or interpretation. The contents of this paper are the responsibility of URC and do not necessarily reflect the views of USAID.

\section{Authors' contribution}

ES structured the manuscript, wrote major sections including introduction, abstract, results, and discussion. She advised data analysis and coordinated inputs from co-authors. SKK cleaned and managed the data, plotted charts, as well as did copy editing. RP analysed the data, wrote parts of data analysis, contributed to results section and prepared tables. AS contributed to writing the introduction and discussion, interpretation of some of the results, especially in writing the specifics of the intervention- the "hows" and "whats" in the ground. SK contributed to the interpretation of some of the results, and in writing the specifics of parts of the intervention. RS provided inputs into the methodology and description of intervention. She also provided insight in the discussion of results. MR contributed to developing the intervention, selected indicators for improvement, contributed to the methodology section, and provided critical review of the manuscript. $\mathrm{NL}$ contributed to design and development of the intervention, provided references and inputs into Ql, and provided critical review of the manuscript. All authors read and approved the final manuscript.

\section{Competing interests}

The authors declare that they have no competing interests.

\section{Consent for publication}

Not applicable.

\section{Ethics approval and consent to participate}

The data pertain to an intervention project and are taken from hospita records and hence no ethical clearance was required. However due permission was obtained from all hospital, state health, and district health officials before starting the intervention.

\section{Publisher's Note}

Springer Nature remains neutral with regard to jurisdictional claims in published maps and institutional affiliations.

\section{Author details}

${ }^{1}$ Consultant, University Research Company, India Pvt. Ltd B7, 1st floor, Suncity, Gurgaon 122002, Haryana, India. '2Data Manager, University Research Company, India Pvt. Ltd, T8-502 Amrapali Grand Sector Zeta 1, Greater Noida 201306, UP, India. ${ }^{3}$ Consultant, University Research Company, India Pvt. Ltd. E 5, NTRO scientist Hostel, Behind Sahastra Seema Bal, Aya Nagar, Delhi 110047, India. ${ }^{4}$ Senior Advisor, University Research Company, 1st floor, LMR House, S-16, Uphaar Commercial Complex, Green Park Extension, New Delhi 110016, India. ${ }^{5}$ Doctoral Fellow (Social Epidemiology), Humanities and Social Sciences Discipline, Indian Institute of Technology, Gandhinagar, India. ${ }^{6}$ LeadQuality and Process Improvement, ACCESS Health International, Nilgiri building, IIIT, Gachibowli, Hyderabad, India. ${ }^{7}$ Project Director, University Research Company, Plot 40, Ntinda II Road, Kampala, Uganda. ${ }^{8}$ Project Director, University Research Company, 1st floor, LMR House, S-16, Uphaar Commercial Complex, Green Park Extension, New Delhi 110016, India.

Received: 27 December 2016 Accepted: 25 April 2017

Published online: 02 May 2017

References

1. Ministry of Health and Family Welfare, Government of India. Family welfare statistics in India. 2011. Available from http://mohfw.nic.in/WriteReadData/ |892s/3503492088FW\%20Statistics\%202011\%20Revised\%2031\%2010\%2011.pdf.

2. Randive B, Diwan V, De Costa A. India's conditional cash transfer programme (the JSY) to promote institutional birth: is there an association between institutional birth proportion and maternal mortality? PLoS One. 2013;8(6):e67452.

3. Chaturvedi S, De Costa A, Raven J. Does the Janani Suraksha Yojana cash transfer programme to promote facility births in India ensure skilled birth attendance? A qualitative study of intrapartum care in Madhya Pradesh. Global Health Action. 2015;8,10.3402/gha.v8.27427.

4. Sri BS, Sarojini N, Khanna R. An investigation of maternal deaths following public protests in a tribal district of Madhya Pradesh, central India. Reprod Health Matters. 2012;20(39):11-20. doi:10.1016/S0968-8080(12)39599-2.

5. Chaturvedi S, Randive B, Diwan V, De Costa A. Quality of obstetric referral services in India's JSY cash transfer programme for institutional births: a study from Madhya Pradesh province. PLoS One. 2014;9(5):e96773.

6. Malhotra S, Zodpey SP, Vidyasagaran AL, Sharma K, Raj SS, Neogi SB, Pathak G, Saraf AJ. Assessment of essential newborn care services in secondary level facilities from two districts of India. J Health Popul Nutr. 2014;1:130-41.

7. Pagel C, Prost A, et al. Is essential newborn care provided by institutions and after home births? analysis of prospective data from community trials in rura south Asia. BMC Pregnancy Childbirth. 2014;14:99. doi:10.1186/1471-2.

8. Berman P, Pallas S, Smith AL, Curry L, Bradley May EH. Improving the Delivery of Health Services: A Guide to Choosing Strategies. Health, Nutrition and Population discussion paper. Washington, DC: World Bank; 2011. [cited 2016 Mar 11]. Available at: http://siteresources.worldbank.org/HEALTHNUTRITION ANDPOPULATION/Resources/281627-1095698140167/ImprovingDeliveryof HealthServicesFINAL.pdf.

9. Government of India. Ministry of Health and Family Welfare. A strategic approach to Reproductive, Maternal, Neonatal, Child and Adolescent Health $(\mathrm{RMNCH}+\mathrm{A})$ in India; 2013 January [cited 2016 Mar 11]. Available from: http://nhm.gov.in/images/pdf/programmes/rmncha-strategy.pdf

10. The Maternal and Child Health Integrated Program (MCHIP). India's Reproductive, Maternal, Neonatal, Child and Adolescent Health Strategy. A case of extraordinary government leadership; 2014 July [cited 2016 Mar 11]. Available from: http://www.mchip.net/sites/default/files/RMNCH + A\%20in\%20lndia.pdf.

11. Government of India. National Health Systems Resource Centre. National Convention on Quality in Public Health 3-4 November 2014 [cited 2016 Mar 11]. Available from: http://nhsrcindia.org/index.php?option=com_ content\&view=article\&id=383: national-convention-on-quality-in-publichealth-03-04-november-2014\&catid=252:home-box\&ltemid $=732$

12. Batalden PB, Davidoff $F$. What is "quality improvement and how can it transform health care. Qual Saf Health Care. 2007:16:2-3. doi:10.1136/qshc.2006.022046.

13. Massoud R, Askov K, Reinke J, Franco LM, Bornstein T, Knebel E, MacAulay C. A modern paradigm for improving healthcare quality, QA monograph series 1. Bethesda, Maryland: Quality Assurance Project for the US Agency for 
International Development (USAID); 2001. [cited 2016 Mar 11. Available at: https:/wwww.usaidassist.org/sites/assist/files/modernparadigm_2001_0.pdf.

14. Singh R, Singh M, Jha R, Sharma P, Livesley N. Improving Quality in Healthcare: A practical guide for health care providers, Technical Report. Published by the USAID ASSIST Project. Bethesda, MD: University Research Co., LLC (URC); 2016. https://www.usaidassist.org/resources/ improving-quality-healthcare-practical-guide-health-care-providers.

15. Indian Council of Medical Research. Ethical guidelines for biomedical research on human participants. Indian Council of Medical Research (2006), New Delhi 110029 http://icmr.nic.in/ethical_guidelines.pdf.

16. Penfold RB, Zhang F. Use of interrupted time series analysis in evaluating health care quality improvements. Acad Pediatr. 2013;13:S38-44.

17. Biglan A, Ary D, Wagenaar AC. The value of interrupted time-series experiments for community intervention research. Prev Sci. 2000;1:31-49.

18. Shadish W, Cook T, Campbell D. Experimental and quasi-experimental designs for generalized causal inference. Boston: Mass: Houghton Mifflin; 2002.

19. van den Broek N, Graham W. Quality of care for maternal and newborn health: the neglected agenda. BJOG Int J Obstet Gynaecol. 2009;116:18-21. doi:10.1111/j.1471-0528.2009.02333.

20. Dettrick Z, Firth S, Soto EJ. Do strategies to improve maternal and child health care in lower and middle income countries lead to improved outcomes? a review of the evidence. PLoS One. 2013;8(12):e83070. doi: 10.1371/journal.pone.0083070

21. Raven J, Hofman J, Adegoke A, van den Broek N. Methodology and tools for quality improvement in maternal and newborn health care. Int J Gynaecol Obstet. 2011;114:4-9.

22. Pirkle CM, Dumont A, Zunzunegui M-V. Criterion-based clinical audit to assess quality of obstetrical care in low- and middle-income countries: a systematic review. Int J Qual Health Care. 2011;23:456-63.

23. Opiyo N, English M. In-service training for health professionals to improve care of the seriously ill newborn or child in low and middle income countries (Review). Cochrane Database of Systematic Reviews. 2010;CD:007071.

24. Lonkhuijzen L, Dijkman A, van Roosmalen J, Zeeman G, Scherpbier A. A systematic review of the effectiveness of training in emergency obstetric care in low-resource environments. BJOG. 2010;117:777-87.

25. Liker JK. The Toyota Way: 14 management principles from the World's greatest automaker. New York: McGraw-Hill; 2004.

26. Ohno T. Toyota production system: beyond large-scale production. New York: Productivity Press; 1988

27. Sharma D, Sharma P, Livesley N. Improving the process of antenatal care to increase detection of women with high-risk conditions in zonal hospital of Mandi, Himachal Pradesh, India, Case study. Bethesda, Maryland: University Research Co., LLC; 2014. [cited 2016 Apr 6]. Available at: https://www. usaidassist.org/sites/assist/files/india_improving_the_process_of_anc_ mandi_may_2014.pdf.

28. Mwaniki M, Vaid S, Chome I, et al. Improving service uptake and quality of care of integrated maternal health services: the Kenya kwale district improvement collaborative. BMC Health Serv Res. 2014;14:416.

29. lyengar K, Jain M, Thomas S, Dashora K, Liu W, et al. Adherence to evidence based care practices for childbirth before and after a quality improvement intervention in health facilities of Rajasthan. India BMC Pregnancy Childbirth. 2014;14:270. doi:10.1186/1471-2393-14-270.

30. Chopra M, Arora N, Livesley N. Improving post-partum care in a large hospital in New Delhi, India, Case study. Bethesda, Maryland: University Research Co., LLC; 2014. [cited 2016 Apr 6]. Available at: https://www. usaidassist.org/sites/assist/files/india_improving_postpartum_care_in_a_ delhi_hospital_sept2014_ada.pdf.

31. USAID Applying Science to Strengthen and Improve Systems Project. Changes that improved maternal and neonatal health in six states of India. Case study. Bethesda, Maryland: University Research Co., LLC; 2015 [cited 2016 Apr 6]. Available at: https://www.usaidassist.org/resources/ changes-improved-maternal-and-neonatal-health-six-states-india.

\section{Submit your next manuscript to BioMed Central and we will help you at every step:}

- We accept pre-submission inquiries

- Our selector tool helps you to find the most relevant journal

- We provide round the clock customer support

- Convenient online submission

- Thorough peer review

- Inclusion in PubMed and all major indexing services

- Maximum visibility for your research

Submit your manuscript at www.biomedcentral.com/submit
Biomed Central 